\title{
Gastrointestinal stromal tumor: a bridge between bench and bedside
}

\author{
Toshirou Nishida ${ }^{1,2}$, Tsuyoshi Takahashi ${ }^{2,3}$, and Yasuaki Miyazaki ${ }^{2}$ \\ ${ }^{1}$ Department of Surgery, Osaka Police Hospital, 10-31 Kitayama-cho, Tennouji-ku, Osaka 543-0035, Japan \\ ${ }^{2}$ Department of Surgery, Osaka University Graduate School of Medicine, Osaka, Japan \\ ${ }^{3}$ Department of Surgery, Osaka General Medical Center, Osaka, Japan
}

\begin{abstract}
Gastrointestinal stromal tumor (GIST) is considered to be driven by a gain-of-function mutation in the KIT or PDGFRA gene. Cure can be obtained only by complete surgical removal of the GIST; however, imatinib, an inhibitor of KIT and PDGFRA, is indicated for advanced, recurrent, and/or metastatic GISTs. Imatinib exhibited remarkable clinical effects on advanced GISTs, with substantial tolerability. Its efficacy greatly depends on the genotype of GIST. The drug, however, met intrinsic or acquired resistance during the treatment, of which the molecular mechanisms were mostly dependent on the genotype of GIST, including primary mutations or secondary mutations in the kinase domains of the corresponding target genes, respectively. Although sunitinib had substantial effects on imatinib-resistant GIST, this drug also encountered primary or secondary resistance depending on the genotype. Thus, advanced GIST may require multidisciplinary treatment. Because resistance mechanisms show some regularity, it is hoped that, in the near future, we may be able to develop a new drug to which resistance does not occur easily, based on scientific evidence.
\end{abstract}

Key words KIT - PDGFRA - Imatinib - Sunitinib . Resistance

\section{Introduction}

Overview of GIST: roles of surgery and target agents

Although gastrointestinal stromal tumors (GISTs) are relatively infrequent cancers in the gastrointestinal (GI) tract, GISTs are the most common mesenchymal tumors in the GI tract $[1,2]$. Clinically, GIST has an incidence of 10-20/million per year and shows no ethnic or gender differences. Primary GISTs are located mainly in the stomach $(60 \%-70 \%)$ and small intestine $(20 \%-30 \%)$,

Offprint requests to: T. Nishida

Received: September 27, 2009 / Accepted: October 9, 2009 and a few (less than 5\%) are found in the colon and the esophagus, and even in peritoneal tissues, including the mesentery, retroperitoneum, and omentum. On immunohistochemical examination, most GISTs (95\%) express KIT protein and only a few (5\%) do not. The latter, called KIT-negative GISTs, may have mutations either in the PDGFRA gene or the KIT gene, with the expression of KIT protein at a very low level that cannot be detected by immunohistochemistry. Until recently, there had been no effective treatment for advanced and recurrent GISTs, which have been subjected to repeated but hopeless struggles with surgery, because GISTs are resistant to conventional chemotherapy and radiotherapy. A decade ago, gain-of-function mutations in the KIT gene, a monumental milestone, were found in most sporadic GISTs [3, 4], followed by the discovery of similar gain-of-function mutations in the PDGFRA gene, a sibling gene of KIT [5,6]. Since then, target agents, including imatinib mesylate (Glivec; Novartis, Basel, Switzerland) and sunitinib malate (Sutent; Pfizer, New York, NY, USA) have been clinically developed. Now, GIST has become a model of targeted therapy for solid tumors, as imatinib has become the first-line treatment for advanced GISTs [2, 7-9].

However, even in an era of molecular-targeted therapy, the primary treatment for GIST is still complete resection by surgery, if it is resectable. Nonetheless, most tumors are clinically diagnosed as abdominal tumors or submucosal tumors (SMTs) before operation, and the diagnosis of GIST is frequently made after surgery by pathological examinations with KIT immunostaining or, less frequently, by genotyping. GIST grows expansively and has infrequent symptoms and signs until it is at an advanced stage, which may result in its being metastatic or at an advanced stage when it is found. GIST mainly metastasizes to the liver hematogenously and/or disseminates in the peritoneal cavity, but rarely shows lymphatic involvement. In Japan, the cancer screening systems may detect relatively small 
SMTs incidentally. These tumors are frequently found as asymptomatic SMTs. When asymptomatic and small SMTs are detected by the screening, the guidelines suggest surgery when SMTs show growth during follow up and clinically malignant features such as irregular margins, ulcer formation, and inhomogeneous parenchyma by echo or computed tomography (CT) scan [9]. Small and asymptomatic SMTs without these features may be followed by periodic endoscopic examinations (Fig. 1). These tumors may be good candidates for laparoscopic surgery as long as the principles of GIST surgery are kept. The roles of laparoscopic surgery in GIST and other cancers are expanding, but this should be discussed separately. The principles of GIST surgery include macroscopically complete resection with safety margins of at least 1 to $2 \mathrm{~cm}$, partial resection with careful consideration of preservation of organ function, no prophylactic lymph node dissection, and avoiding injuries to the tumor pseudocapsule, as well as avoiding tumor rupture by surgical manipulation [7,9].

When GISTs are inoperable or when achieving curative surgery is difficult, or when there are evident metastases or relapses, imatinib, a selective inhibitor of KIT and PDGFRs, is recommended as the first-line treatment of KIT-positive GIST [7-9]. Although imatinib has shown substantial improvements in the prognoses of patients with advanced GIST, nearly $10 \%$ of GISTs show primary resistance to imatinib, $5 \%$ of patients exhibit intolerance to imatinib, and half of the patients experience disease progression in the 2-3 years after commencing imatinib [2, 10-15]. Sunitinib, an oral, multitargeted receptor tyrosine kinase inhibitor of KIT, platelet-derived growth factor receptor-alpha and -beta (PDGFR- $\alpha$ and $-\beta$ ), vascular endothelial growth factor receptors (VEGFR-1, -2, and -3), FMS-like tyrosine kinase-3 receptor (FLT3), colony-stimulating factor 1 receptor (CSF-1R), and glial cell line-derived neutrophic factor receptor (RET), is approved for the treatment of advanced GIST after the failure of imatinib $[16,17]$.

This article will focus on recent advances in GIST therapy, focusing especially on molecular-targeted therapy and its fundamental mechanism of efficacy and resistance.

\section{Pathogenesis of GIST and mechanism of its proliferation}

\section{A quick review of GIST oncogenesis and proliferation}

Approximately $90 \%-95 \%$ of GISTs are associated with and thus are driven by oncogenic mutations in either the KIT or the PDGFRA gene; these genes encode similar type III receptor tyrosine kinases: KIT or PDGFR- $\alpha$, respectively $[18,19]$. Both genes are located on chromosome 4 (4q11-q12) nearby. Mutations in the KIT or PDGFRA gene induce dimerization and autophosphorylation of the corresponding tyrosine kinase without the binding of their ligands,

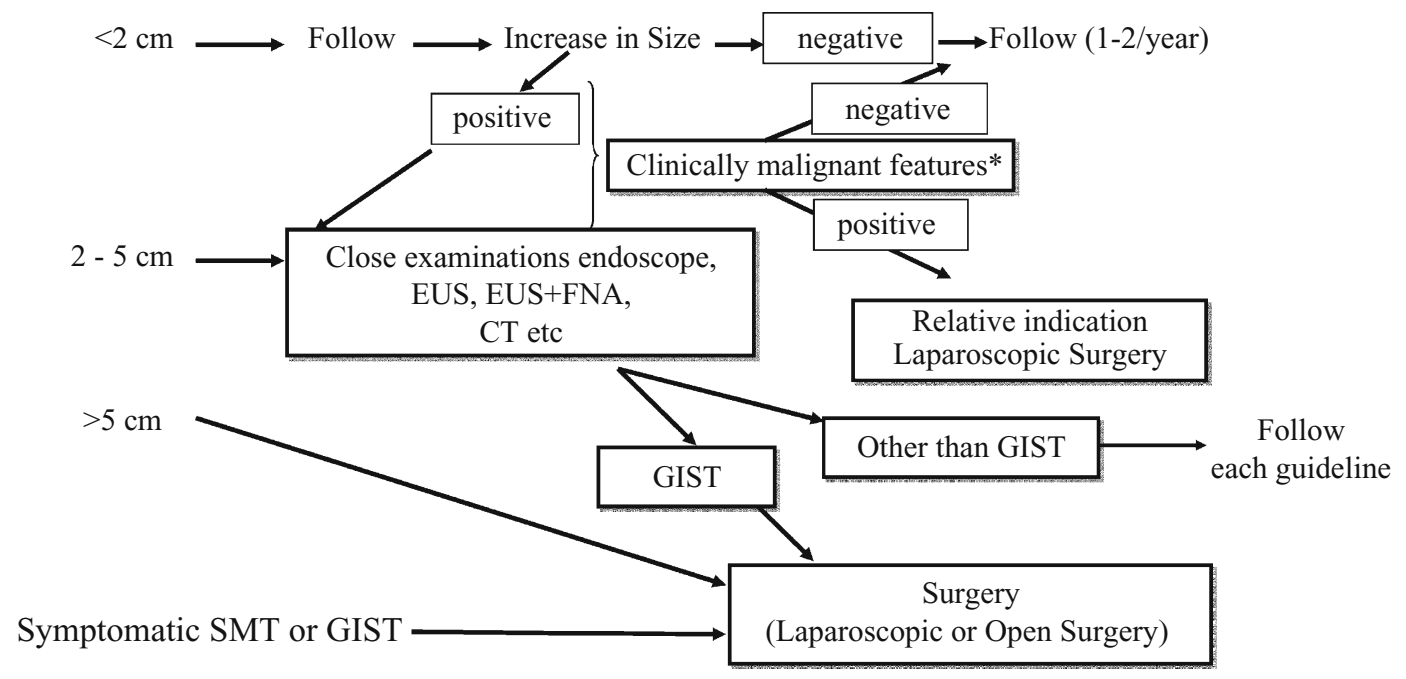

Nishida et. al. Int J Clin Oncol. 2008

Fig. 1. Approaches to submucosal tumor (SMT) or abdominal mass including gastrointestinal stromal tumor (GIST). According to the Japanese GIST guidelines [9], strategies for incidentally found SMTs and GISTs are shown. Asterisk, clinically malignant features include irregular margins, inhomogeneous parenchyma, and ulcer formation. EUS, endoscopic ultrasonography; $F N A$, fine-needle aspiration; $C T$, computed tomography. Adapted from reference 9, with permission 
stem cell factor and platelet-derived growth factors, respectively.

In the remaining small subgroups of GISTs (wildtype GISTs; $5 \%-10 \%$ ) it has been suggested that mutations in the neurofibromatosis type 1 (NF1) gene in neurofibromatosis-associated GISTs, amplification of the insulin-like growth factor 1 receptor (IGF1R) in juvenile GISTs with typical clinical features, and b-Raf (BRAF) mutations may contribute to neoplastic proliferation; of note, the expression of KIT and its phosphorylation have been observed even in wild-type GISTs $[15,18,19]$.

\section{KIT and PDGFRA mutations in sporadic GISTs}

Mutations in the KIT or PDGFRA gene are mutually exclusive, and cause ligand-independent constitutive activation of the corresponding receptor tyrosine kinase, KIT or PDGFR- $\alpha$, respectively, and subsequently activate common downstream signaling pathways, including ERK kinases, PI3kinase-mTOR pathways, and STATs pathways. Primary and untreated GIST carries only a single mutation of either the KIT $(75 \%-80 \%)$ or the PDGFRA ( 10\%) gene. In KIT, four hot spots have been identified, i.e., exon 9, exon 11, exon 13, and exon 17 , and three hot spots, exons 12,14, and 18, have been identified for PDGFRA. KIT mutations in primary GISTs were most frequently found in the juxtamembrane domain (exon 11, 60\%-70\%), followed by the extracellular domain (exon 9;6\%-10\%), but were rarely found in two kinase domains (exons 13 and 17) [18-22]. Similarly, $10 \%-15 \%$ of GISTs have PDGFRA mutations either in the juxtamembrane domain (exon 12, $2 \%-3 \%$ ) or in the kinase domain (exon $14, \sim 1 \%$; exon $18,10 \%)$ [19, 21-24]. GISTs with mutations in the PDGFRA gene are mostly found in the stomach. Pathological examinations have revealed predominant epithelioid tumor cells in a myxoid stromal background, which sometimes express KIT protein weakly. PDGFRA mutations are found in more than $10 \%$ of primary GISTs and $5 \%-10 \%$ of recurrent GISTs. GISTs with PDGFRA mutations show relatively indolent clinicopathological features. Approximately $5 \%-10 \%$ of GISTs have no mutation in either the KIT or the PDGFRA gene (Fig. 2).

KIT exon 9 mutation is found exclusively in intestinal GISTs with spindle-cell shape tumor cells and these GISTS show aggressive clinicopathological features [18]. Exon 9 (and exon 8) encode the extracellular domain just beneath five immunoglobulin-like loops (Fig. 2) and mutations in these exons may facilitate receptor dimerization. Exon 9 mutations are almost always the insertion of six base pairs, a duplication of Ala and Tyr, and are detected in $5 \%-10 \%$ of primary GISTs [24] and in $10 \%$ to $15 \%$ of relapsed or advanced
GISTs [18, 20-22]. Mutations in this region may, thus, render KIT protein prone to dimerization. Mutations in the extracellular domain appear to be still stabilized in an autoinhibited form.

KIT exon 11 and PDGFRA exon 12 form the juxtamembrane domain. This domain in both genes not only interacts with the activation loop to stabilize the kinase in an autoinhibited form but interacts with receptor dimerization [25]. Any type of mutation in this domain resulting in loss of its functions leads to conformational changes, to instability of the autoinhibited form, and to the loss of the inhibitory function for dimerization. Thus, various types of mutations, such as missense mutations and insertion and deletion mutations, are found in this region. GIST with KIT exon 11 or PDGFRA exon 12 mutation is found throughout the GI tract. Interestingly, internal tandem repeat mutations in the distal part of KIT exon 11 are infrequent, but are predominantly found in female stomach, and GISTS with these internal tandem repeat mutations show relatively indolent clinical features $[18,26]$. Mutations in the juxtamembrane domain tend to be stabilized in an autoinhibited form under unactivated conditions.

Mutations in the kinase domains are uncommonly found in KIT exon 13 or 17 as well as in PDGFRA exon 14 or 18. Most mutations are a missense mutation. Most of the mutations in these domains, especially in the ATP-binding domain, found in primary GISTs seem to be in an autoinhibited form under unactivated conditions, as seen in exon 9 or 11 mutations, and only the two types of mutations, D816H/V of KIT and D842V of PDGFRA, show strong conformational equilibrium to the activated form. In general, the kinases preferentially stabilized in the autoinhibited form under unactivated conditions are usually sensitive to both imatinib and sunitinib, while the kinases stabilized in the activated form are extremely resistant to both drugs [27].

Some reports have indicated that GISTs with deletion mutations in and around KIT exon 11 codon 557-558, where the juxtamembrane domain mainly interacts with kinase domains and has inhibitory effects on receptor phosphorylation and activation, showed aggressive clinicopathological features and poor prognosis; however, other studies did not $[1,18,19,28]$. In addition, loss of heterozygosity in the KIT locus, that is, a shift from heterozygosity to homozygosity, which was caused by the deletion of wild-type KIT and was sometimes associated with an increase in the copy number of mutated KIT, was reported to be associated with high proliferative activity and metastatic potential $[29,30]$. All these reports were small studies, so further investigations are required to reach a consensus on genotyping and clinicopathological aggressiveness. 


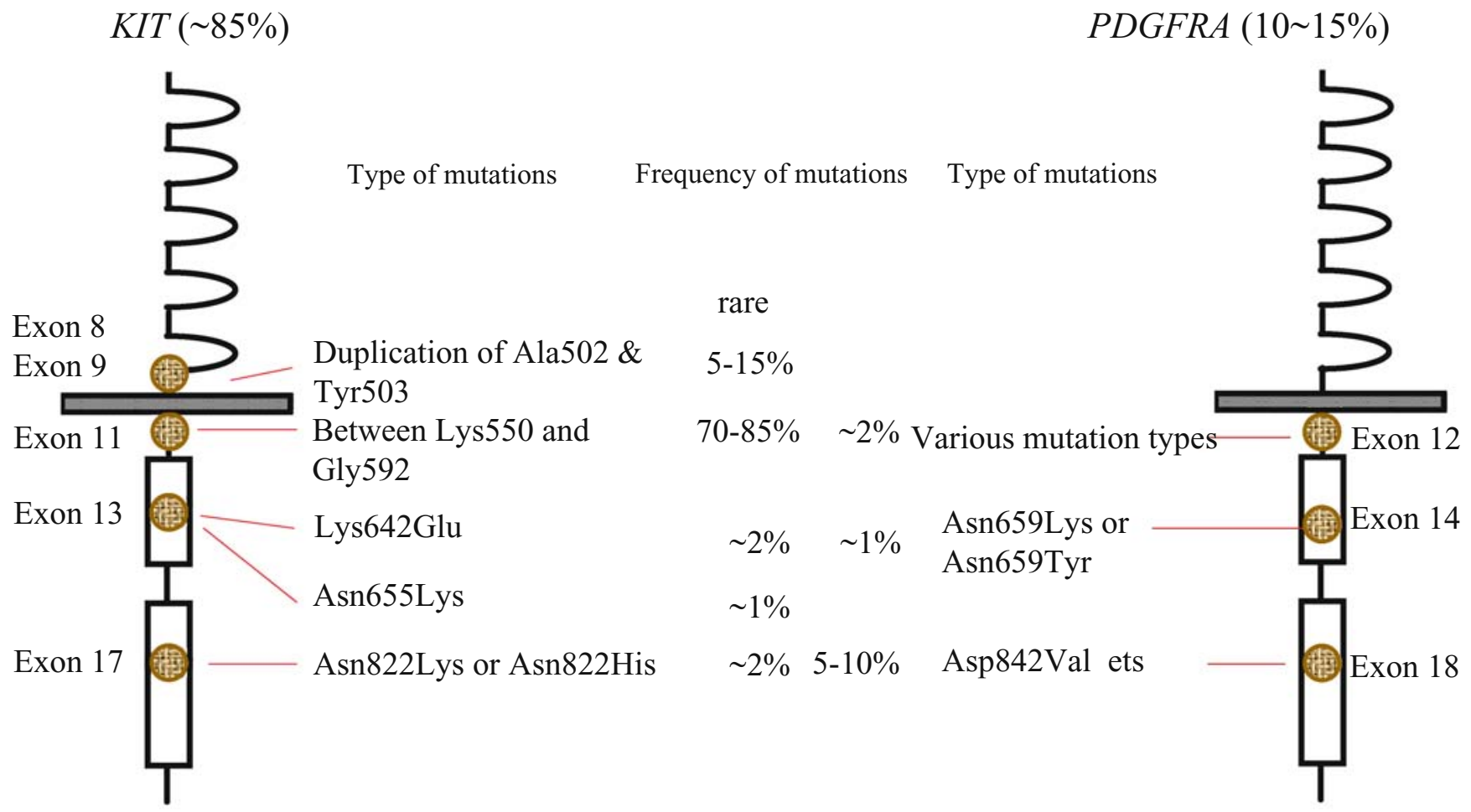

No mutation: 5\%-10\% (juvenile GIST, NF-1 GIST)

Fig. 2. Mutations in the $K I T$ and $P D G F R A$ genes. Several types of mutations found in primary GISTs and their frequency are shown. $N F-1$, neurofibromatosis type 1

\section{Germline mutations in the KIT and PDGFRA genes cause familial GISTs}

Concerning familial GIST, germline mutation in the KIT or PDGFRA gene was first reported in 1998 [3], the same year that KIT mutations in sporadic GIST were reported [4]. Since then, at least 22 pedigrees have been reported with germline mutations in KIT exon 8 (1 pedigree), exon 11 (13 pedigrees), exon 13 (2 pedigrees), exon 17 (3 pedigrees), PDGFRA exon 12 (2 pedigrees), and exon 18 (1 pedigree; Table 1) [31-51]. Inheritance is autosomal dominant with high penetrance (more than 90\%) [52]. The median age of onset (age 44 years) of familial GISTs is younger than that of sporadic GIST (60 years) without gender difference. In these patients, multiple and low-to-intermediate-risk GISTs have been seen in the small intestine, the stomach, and rarely in the colon. Members of four families with germline mutations in KIT exon 8 or 17 showed motility disorders of the GI tract including dysphagia and constipation. Importantly, histopathological examinations revealed that most family members had microscopically diffuse proliferation of strongly KIT-expressing cells in the myenteric plexus of normal-appearing GI tract. These results are very consistent with findings in knock- in mice [53, 54], suggesting that GIST originates from immature mesenchymal cells of the same lineage as the interstitial cells of Cajal, a pacemaker cell of the GI tract. Other distinctive features of familial GISTs are skin pigmentation and skin disorders. Some family members had cutaneous mastocytosis, urticaria pigmentosa, and, rarely, melanoma. Somatic mutations in the KIT gene were reported to have a role in the oncogenesis and progression of sporadic mastocytosis and melanoma [55-57].

In spite of the early onset, fewer than $20 \%$ of patients with familial GIST die of the disease [52] suggesting that most family members have low-grade risk GISTs. Furthermore, $10 \%-20 \%$ of normal patients over the age of 60 , who underwent gastrectomy due to gastric cancer, are reported to have microscopic and multiple GISTs in the upper stomach [58-60], which also harbor mutations in the KIT gene [58,59]. Activating mutations in the KIT gene are suggested to be acquired very early in the development of most sporadic GISTs, and KIT mutations per se are thought to be of little importance in malignant transformation [61]. These results suggest that mutations in the KIT or PDGFRA gene are involved in the oncogenesis and proliferation of GIST, but not in malignant changes. 


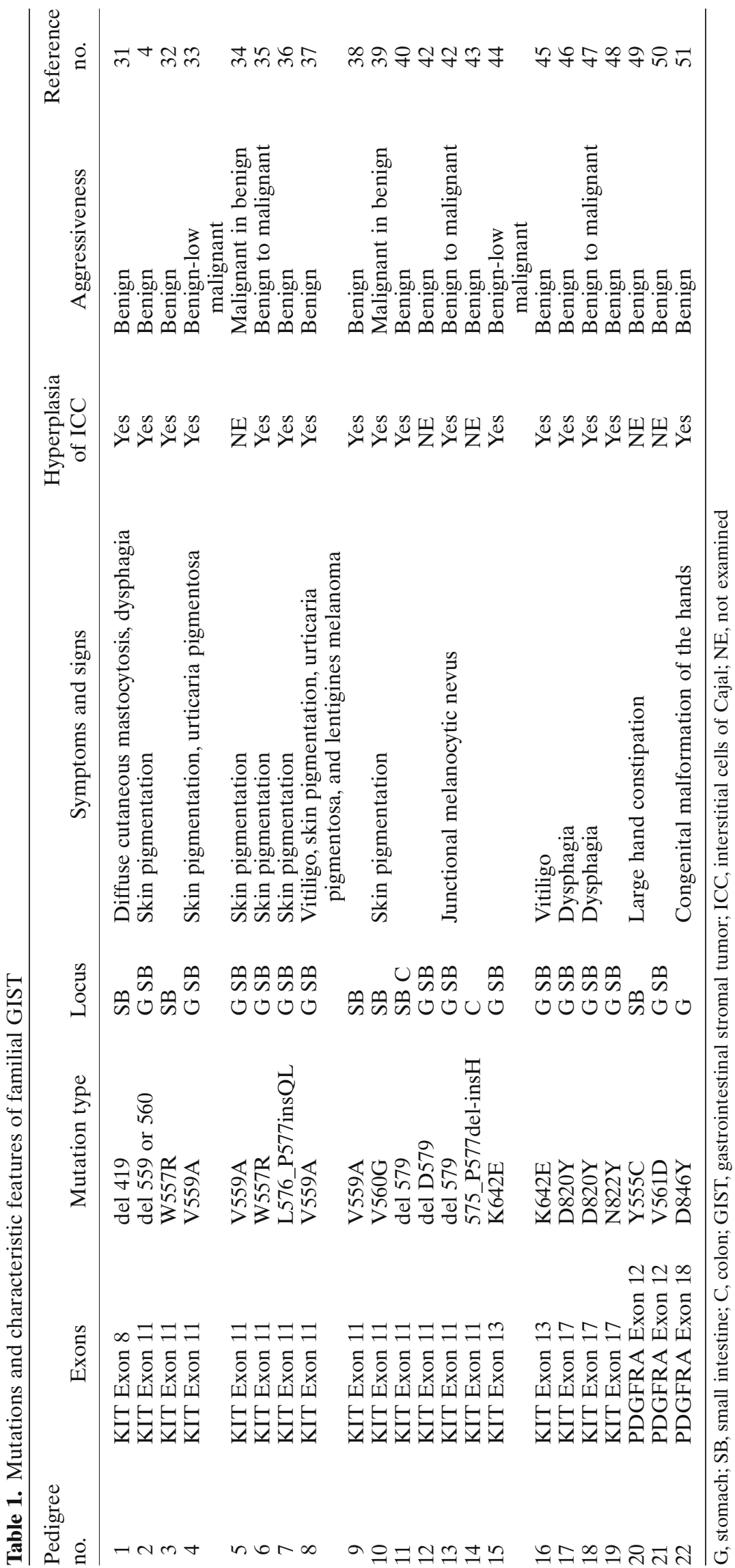




\section{Mechanism of action of imatinib and clinical results}

Imatinib, a derivative of 2-phenylaminopyrimidine, has been developed as an agent targeted for the BCR-ABL protein, which is responsible for oncogenesis and proliferation of chronic myelogenous leukemia. Imatinib also inhibits ABL, KIT, and PDGFRs, and the latter two are targets of GIST. Imatinib is very water-soluble, is rapidly absorbed from the GI tract, and its bioavailability is high (98\%). Imatinib mainly binds to serum proteins such as albumin and $\alpha 1$-acid glycoprotein, in the blood, and is metabolized by the cytochrome $\mathrm{P} 450$ system, including CYP3A4 and other cytochromes, of the liver (Table 2). The half-lives of imatinib and its main metabolite are $16-18 \mathrm{~h}$ and $40 \mathrm{~h}$, respectively. The main metabolite, $N$-demethylated piperazine derivative, is also active.

Sunitinib, a derivative of oxindole, is an oral, smallmolecule, multitargeted receptor tyrosine kinase inhibitor. Sunitinib inhibits VEGFR-1,-2, and -3 in the order of Ki: 1, $3>2$ ), PDGFRA, PDGFRB > KIT > RET and FLT-3 [17]. Sunitinib appears to be less bioavailable than imatinib, and its binding to serum proteins and metabolic pathways is very similar to that of imatinib. The half-lives of sunitinib and its main metabolite are $40-50 \mathrm{~h}$ and $80-110 \mathrm{~h}$, respectively. Although sunitinib has both direct inhibitory effects on KIT and PDGFRA expressing on GIST tumor cells and indirect inhibitory effects via the inhibition of tumor angiogenesis and reduction of blood flow through the inhibition of VEGFR and PDGFR signals, recent data have indicated that direct KIT or PDGFRA inhibition is a principal action for GIST [62, 63]. This will be discussed later.

Both imatinib and sunitinib, which are competitive inhibitors of ATP, enter the ATP-binding pocket of KIT and PDGFRA kinases. These drugs bind to the autoinhibited form, but not the activated form, of these receptor tyrosine kinases, then reversibly inhibit auto- phosphorylation as well as activation of the kinases, resulting in the silencing of downstream intracellular signaling pathways. The two drugs, however, have different binding loci and modes. Imatinib interacts with several amino acid residues both in the ATP-binding pocket and in the activation loop, and sunitinib may interact with different residues in the ATP-binding pocket [64], which may result in different inhibitory activities of the two drugs.

\section{Clinical trials of imatinib}

A number of clinical studies have demonstrated the efficacy and tolerability of imatinib at the recommended dose of $400 \mathrm{mg} /$ day for advanced, metastatic, or recurrent GIST [10-14, 65]. In the clinical trials, complete responses (CRs) were rarely observed (1\%), and most patients showed a partial response (PR, 4\%$70 \%$ ) or stable disease (SD, $20 \%$ ). The progressionfree survival (PFS) of patients with long SD (SD of more than 6 months) was very similar to that of patients with a PR [12]. After 6 months of imatinib therapy, if a patient did not experience progressive disease (PD), the patterns of radiological responses $(\mathrm{CR}, \mathrm{PR}$, and long SD), determined by tumor size criteria such as RECIST (response evaluation criteria in solid tumors) had no prognostic value for further outcome, and it was recommended that imatinib needed to be continued as long as there was no progression according to RECIST [66]. The disease control rate was nearly $85 \%$. Thus, only $10 \%-15 \%$ of patients with advanced GIST suffered from PD, and up to $5 \%$ did not tolerate imatinib. A comparison of two doses of imatinib $(400 \mathrm{mg} /$ day vs $800 \mathrm{mg} /$ day) by the European Organization for Research and Treatment of Cancer (EORTC)/intergroup and US S0033 trials indicated that both doses resulted in similar response rates and overall survival (OS) [11, 14], suggesting that the recommended dose be $400 \mathrm{mg}$ /day. However, the higher dose ( $800 \mathrm{mg} / \mathrm{day})$

Table 2. Pharmacokinetic parameters of imatinib and sunitinib

\begin{tabular}{lll}
\hline & \multicolumn{1}{c}{ Imatinib mesylate } & Sunitinib malate \\
\hline Drug & Tablet & Capsule \\
Targets & BCR-ABL, KIT, PDGFR, ABL & VEGFR, KIT, PDGFR, CSF-1, FLT3, RET \\
Tmax (h) & $\sim 3$ & $\sim 8$ \\
$\mathrm{t} 1 / 2(\mathrm{~h})$ & $\sim 8$ & $40 \sim 50$ \\
Minimal effective dose & $300 \mathrm{mg} \leq$ & $25 \mathrm{mg}<$ \\
Maximal safe dose & $\leq 800 \mathrm{mg}$ & $\leq 50 \mathrm{mg}$ \\
Medication & Oral continuous & Oral interrupted (or continuous) \\
Bioavailability & $>98 \%$ & $55 \%-80 \%$ (in animals) \\
Blood distribution & Binding $>95 \%$ (albumin, $\alpha 1$-acid glycoprotein) & Binding 95\%-90\% \\
Metabolism & Hepatic (CYP3A4) & Hepatic (CYP3A4) \\
First metabolites & Antitumor effects (+) & Antitumor effects (+) \\
\hline
\end{tabular}

PDGFR, platelet-derived growth factor receptor; VEGFR, vascular endothelial growth factor receptor; RET, glial cell line-derived neutrophic factor receptor; Tmax, time that a drug is present at the maximum concentration in serum; $1 / 2$, half-life 
showed better PFS than the $400 \mathrm{mg} /$ day dose in the EORTC/intergroup phase III trial, whereas the two doses showed similar PFS in the US S0033 phase III trial. Finally, a meta-analysis of these two trials suggested that there were no significant differences between the two doses in OS, and that treatment with $800 \mathrm{mg} /$ day imatinib showed significantly longer median PFS when a mutation was found in KIT exon 9 [15]. In fact, in in vitro studies, a higher concentration was required to inhibit the kinase activity of KIT with exon 9 mutations compared to the concentration required to inhibit the kinase activity of KIT with exon 11 mutations [20].

The BFR14 study randomized advanced GIST patients to receive or to stop ongoing imatinib until progression following 1 or 3 years of tumor control with imatinib [67]. The study showed that imatinib interruption was associated with a high risk of disease progression and that median time to progression (TTP) after stopping either 1-year or 3-year treatment with imatinib was similar (6 months), suggesting that imatinib discontinuation could not be recommended in routine practice even if an apparent CR was obtained. When treatment was restarted, fortunately, disease control was reestablished in more than $90 \%$ of such cases and OS as well as time to resistance for imatinib appeared to be similar in the stopping and continuous groups. Recently, a pharmacokinetic analysis of the B2222 study [10] has shown that the lowest quartile of imatinib trough levels showed poor clinical outcomes with a lower clinical benefit rate and shorter TTP than the other three quartiles [68]. Lower doses are reported to be risk factors for early progression of the disease [69]. These data suggest that maintenance of the optimal blood level of imatinib is ideal and that blood level testing may be required for optimizing the clinical outcomes of patients with GIST.

From the subanalyses of several clinical trials, factors affecting effectiveness and outcomes of imatinib therapy were indicated [12, 14, 68, 69]. Among them, performance status (PS), tumor mass volume, gender (better prognosis for females), serum level of albumin, imatinib dose, location of the primary tumor (gastric GIST had better prognosis than intestinal), and genotype were commonly indicated to be prognostic.

\section{Genotyping and clinical efficacy}

The expression of KIT protein did not always correlate with response to imatinib and PFS, although a significant difference was observed in median OS when KIT-positive tumors were compared with KIT-negative tumors (53 vs 31 months) [14]. Rather, genotypes of KIT and PDGFRA were correlated well with response to imatinib, PFS, and OS [13, 20-22]. GIST with KIT exon 11 mutations showed a more desirable response to imatinib, followed by GIST with KIT exon 9 mutations and wild type. Of note, the beneficial effect of the higher dose $(800 \mathrm{mg} /$ day $)$ was confined to GISTs with KIT exon 9 mutations, as described above. The number of patients observed is small, but patients with the PDGFRA mutation of $\mathrm{D} 842 \mathrm{~V}$ are highly resistant both to imatinib and sunitinib $[62,63]$. These results are consistent with in vitro experiments $[6,62,64]$.

With imatinib treatment, the median PFS of patients with advanced GIST appears to be 2 years, and the median OS is approaching 55-57 months, whereas before the imatinib era such patients had an OS of only 9-20 months [12].

\section{Therapy for imatinib-resistant GIST}

When imatinib-resistant GIST is diagnosed, we now have a few treatment strategies. When resistant lesions are limited and resectable by operation with substantial safety, one of the therapeutic choices is complete resection of the resistant lesions and continued imatinib therapy. This may add another 8 months of PFS. When the lesions are unresectable, when surgical treatments have substantial risks, or when resistance is systemic, sunitinib is indicated for patients with a good PS ( 0 or 1). Increase in the imatinib dose to $800 \mathrm{mg} /$ day is an another option to imatinib-resistant GIST. This may add another 3-4 months of PFS. In this review, we will focus on sunitinib.

\section{Clinical trials of sunitinib}

Sunitinib has been approved multinationally for the treatment of patients with imatinib-resistant GIST or those with imatinib intolerance. Sunitinib was administered at $50 \mathrm{mg} /$ day on a 4-weeks-on and 2-weeks-off schedule in clinical trials, although recently continuous daily doses of $37.5 \mathrm{mg}$ /day have been reported to have similar efficacy and tolerability [16, 70]. From several clinical studies, sunitinib showed response rates of 5\%$10 \%$ and long SD (SD of more than 6 months) rates of $2 \%-30 \%$. Thus, the clinical benefit rate $(\mathrm{CR}+\mathrm{PR}+$ long SD) was $30 \%-40 \%$, with a median PFS of 8 months and median OS of 1.5-2 years [71]. Clinical factors affecting outcomes of sunitinib therapy indicated by subgroup analysis of a phase 4 trial were PS, age, and prior imatinib dose (previous higher dose was correlated with a worse prognosis) [15]. More importantly, the KIT or PDGFRA genotype of GISTs appeared to be correlated with the response to sunitinib and the PFS $[62,63]$. The molecular mechanisms of sunitinib resistance are still being investigated. Preliminary results have indicated that genotype and newly developed mutations in the activation loop of the KIT or PDGFRA gene 
appeared to be critical $[62,63]$. This will be discussed below.

\section{Molecular mechanisms of resistance to imatinib and sunitinib}

\section{Diagnosis of resistance}

Half of GISTs under imatinib therapy will show resistance within 2 years. Resistance to imatinib is divided into two categories, primary resistance and secondary resistance. Primary resistance is defined as progression of the disease before any significant effects occur, including CR, PR, and long SD (SD for more than 6 months) and secondary resistance is defined as disease progression after $\mathrm{CR}, \mathrm{PR}$, and long SD.

Primary resistance usually appears as enlargement of preexisting tumors or as the appearance of new lesions as defined by RECIST. Primary resistance was shown to be correlated with the genotype [6,13,20-22]. Resistance to imatinib was frequently seen in GISTs without mutations in the KIT and PDGFRA genes, as well as being seen in GISTs with resistant types of mutations in kinase domains (i.e., D816H/V of KIT and D842V of PDGFRA), and GISTs with KIT exon 9 mutations. Secondary resistance is diagnosed by enhanced $\mathrm{CT}$, as enlargement of tumors, a new nodule in a mass, and/or a new lesion. Lesions with "a nodule-in-a-mass" appearance sometimes show reuptake of fluorodeoxyglucose (FDG) on positron emission tomography (PET). Resistance with "a nodule-in-a-mass" appearance has similar prognostic effects and molecular and pathological features to those of the other two resistance patterns [72].

Secondary resistance is mainly due to secondary mutations of the KIT or PDGFRA gene $(70 \%-80 \%)$, and is partly due to the overexpression of KIT and/or an increase in the copy number of mutated KIT (10\%), as well as being partly due to a gain of new but unknown proliferation mechanisms with a concomitant loss of KIT control (10\%). Secondary mutations and overexpression of KIT are generally termed "target resistance" and the last resistant mechanism with other newly activated systems is generally termed "biological resistance", where KIT expression has disappeared and tumors show the morphological appearance of rhabdomyoblastic differentiation including the expression of desmin [73].

\section{Molecular mechanisms of secondary target resistance}

The histological response of GISTs to imatinib is heterogeneous. Some tumors may show gross tumor necrosis with cystic degeneration and hyalinization, whereas the remaining solid areas contain viable tumor cells. Complete loss of tumor cells with hyalinization is rarely seen. The last fact is very consistent with the results of BFR14, where stopping imatinib even after CR induced disease progression [67]. KIT expression also varies depending on viable tumor cells. In contrast, most imatinib-resistant tumors exhibited solid tumor masses with strong re-expression of KIT [63]. KIT and PDGFRA are type III tyrosine kinases in which the kinase domain splits into domain I (the ATP-binding domain) and domain II (activation loop). The former domain is mainly composed of exons 13 and 14, and the latter consists mainly of exons 16,17 , and 18 . In genetic analyses, almost $80 \%$ of resistant lesions were shown to have second mutations either in the ATP-binding domain or in the activation loop [74-86]. Nearly $10 \%$ of resistant GISTs having no second mutations were shown to have an increased copy number of mutated KIT by fluorescence in situ hybridization (FISH). When secondary mutations were also examined in imatinib-sensitive lesions where various degrees of viable tumors with wide ranges of KIT expression were seen, only a few lesions had secondary mutations [82]. Mathematical models have indicated that, in chronic myelogenous leukemia (CML), most secondary mutations might occur after therapy [87]. Recently, however, others have indicated that most mutations found in resistant clones were found before treatment, although the copy number was extremely small [88]. The latter finding indicates that target agents may suppress or kill only tumor cells with sensitive mutations, and may select resistant clones. Whether ready-made clones with resistant mutations are present before the treatment and are selected by the drugs or whether secondary mutations appear during treatment is still to be settled.

\section{Secondary mutations}

Secondary mutation in the kinase domains is accompanied by concomitant re-activation of the corresponding tyrosine kinase even in the presence of imatinib [74, 89]. Secondary mutations also have hot spots, including KIT exon 13 (codon 654); exon 14 (codon 670); exon 17 of codons 809, 816, 820,823, and 829; and PDGFRA exon 14 and exon 18 (Fig. 3A) [20-22, 74-86]. Secondary mutations in exon 13 of the KIT gene are exclusively missense mutation of V654A. Mutation of V654A decreases the binding capacity of imatinib, although the V654A mutation itself is not suggested to be a gain-offunction mutation [90]. This mutation accounts for $40 \%$ of secondary mutations found. Secondary mutations found in exon 14 are mostly T670I, which is called a gatekeeper mutation, as reported in other diseases and other genes [91-93]. This type of mutation causes steric hindrance for imatinib binding to KIT and also induces 
autophosphorylation of the kinase by itself, suggesting a gain-of-function mutation [94]. In GISTs, this gatekeeper mutation was observed in $10 \%$ of secondary mutations in the KIT gene. Thus, secondary mutations in the ATP-binding domain are mostly confined to the missense mutations in two codons, V654A and T670I, which account for half of the secondary mutations in the KIT gene. KIT or PDGFRA kinase with these mutations in the ATP-binding domain is thought to be stabilized in an autoinhibited form and these forms are sensitive to sunitinib even after they become imatinibresistant [64].

In the activation loop, missense mutations were frequently detected in codons $816,820,822$, and 823 , and a few deletion mutations were reported. Some mutations found in codons D816, D820, and N822 of secondary resistant GISTs had amino acid replacements similar to those found in the primary GIST, while other mutations were novel and specific for resistant GISTs. The substituted amino acids are relatively constant, as shown in Fig. 3, and most of these mutations are thought to cause autophosphorylation and activation of the kinase $[22,62,74]$. Some mutations found in the activation loop may be considered to destabilize the autoinhibited form by negatively influencing the inhibitory conformation of the juxtamembrane domain, resulting in a shift of conformational equilibrium toward the activated form [64]. So, the mutations found in the activation loop sometimes show resistance to both sunitinib and imatinib in vitro and in vivo.

As previously stated, the incidence of secondary mutations was greater in GISTs with initially imatinibsensitive mutations, i.e., GISTS with KIT exon 11 and PDGFRA exon 12 mutations, than in GISTs with the less-sensitive mutation, $K I T$ exon 9 [18, 74, 81]. In fact, our summary of the mutational status of secondary imatinib-resistant GISTs reported in several papers indicated that $60 \%$ of GISTs with primary KIT exon 11 mutations had secondary mutations either in the ATPbinding domain or the activation loop, whereas only one-third of those with a primary KIT exon 9 mutation had second mutations. More than $80 \%$ of primary wildtype GISTs, which are relatively resistant to imatinib, showed no secondary mutation even after secondary resistance was acquired. These results indicate that the inhibitory effects of imatinib may influence the mechanisms of secondary resistance. More interestingly, almost all of the secondary mutations examined were located in the same gene; that is, when primary GISTs have KIT or PDGFRA mutations, secondary mutations were found in the KIT or PDGFRA gene, respectively (Fig. 3B). When no mutation was found in the primary tumor, the GIST still had no mutation even after showing secondary resistance. Furthermore, when the allelic distribution of mutations was examined, it was found that most secondary mutations occurred in the same allele as the primary mutations, suggesting that secondary mutations are cis-mutations (Fig. 3B) [74, 78, $79,81]$. Only a few cases had a second mutation in a different gene and/or a different allele (trans) [74, 86]. Similar cis-mutations in a resistant lesion were also reported in epidermal growth factor receptor (EGFR)mutated non-small cell lung cancer after treatment with gefitinib or erlotinib [95]. These results indicate that some specific mechanisms may be involved in the generation of second mutations.

\section{Sunitinib and genotype}

Sunitinib was used for imatinib-resistant GISTs and was shown to be effective for GISTs with primary wild-type or primary KIT exon 9 mutation [15]. Recently, the correlation between genotype and the efficacy of sunitinib was examined. The reports suggested that GISTs with secondary KIT mutations in the ATP-binding domain (KIT exons 13 and 14) were sensitive to sunitinib, while GISTs with mutations in the activation loop (KIT exons 16,17, and 18 and PDGFRA exon 18) were resistant to sunitinib (Fig. 3B) [62, 63]. These clinical data are very consistent with in vitro data of kinase assays $[62,89]$. The correlation of genotype with sunitinib activity appeared to be true for each metastatic lesion of GIST. However, for an individual person treated with sunitinib, the genotype did not always reflect the clinical outcome of the patient, because each patient may have multiple resistant lesions which have different resistance mechanisms and different secondary mutations, resulting in differing sunitinibsensitivities. Thus, using genotyping, we could not always make correct prognostications for sunitinib, as seen in our findings for imatinib.

\section{Future directions and conclusions}

\section{Multidisciplinary treatment for advanced GISTs}

As described above, we have noted the roles of targeted therapy and its limitations. Cure could not be obtained for advanced GISTs either by surgery alone or by imatinib or sunitinib alone. One ambitious strategy is surgery plus adjuvant therapy for GISTs at high risk of recurrence. Several trials have investigated adjuvant imatinib therapy. From the published data, adjuvant imatinib therapy for 1 year prolonged recurrence-free survival (RFS), especially for high-risk GIST [96]. The RFS was reported to be influenced by genotype, and patients with KIT exon 9 mutations appeared to have a higher chance of recurrence [15]. In the Japanese guidelines [9], the dose of imatinib is $400 \mathrm{mg} /$ day, and target patients may be those with high-risk GISTs and those 


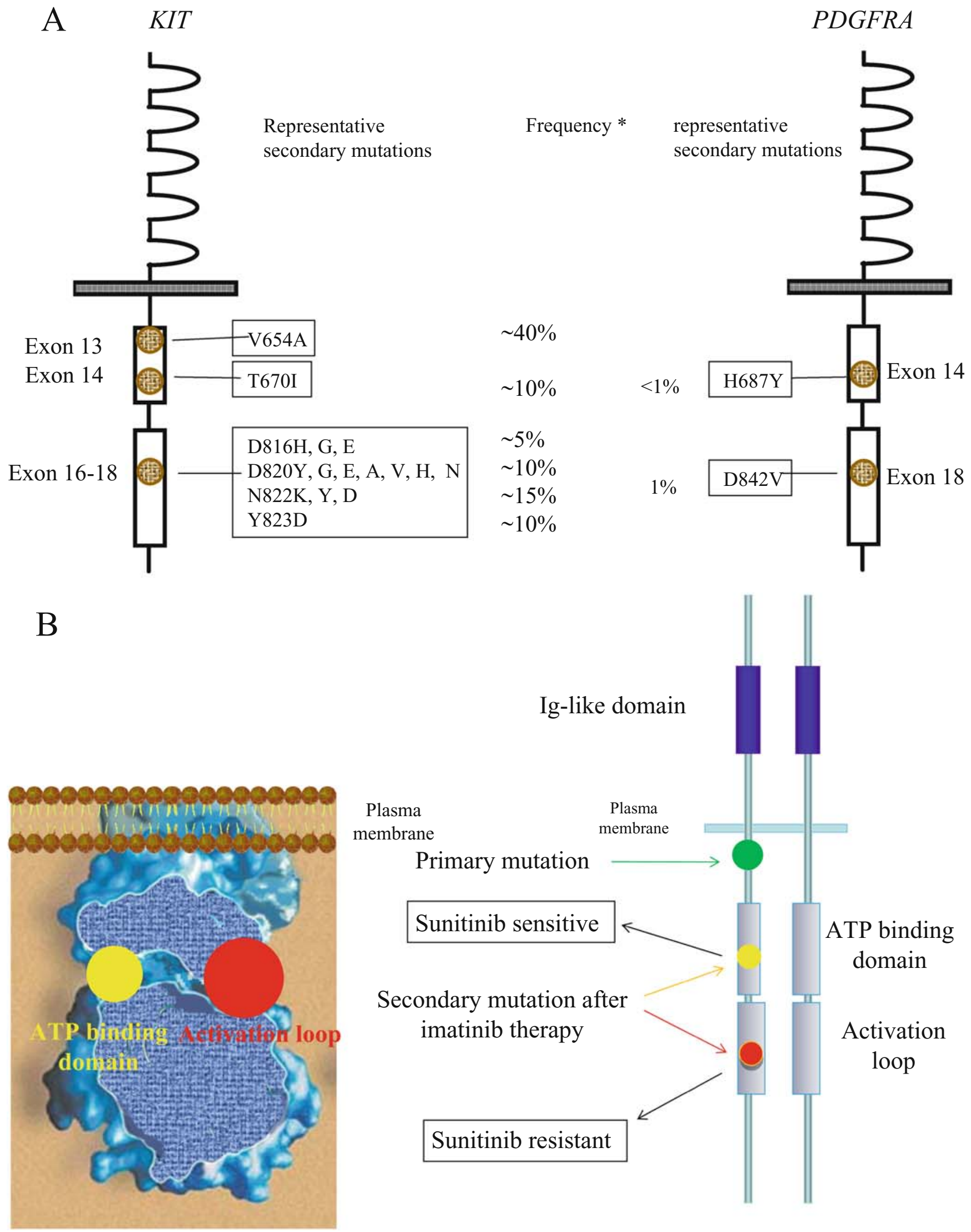

Fig. 3A,B. Secondary mutations in the $K I T$ and PDGFRA genes. A Representative mutations ( $>5 \%$ ) found in secondarily resistant GISTs are shown. Asterisk, the frequency of each mutation type/total secondary mutations was calculated mainly from data obtained from references 75 to 85 . B Schematic illustration of hot spots where secondary mutations preferentially occurred 
with clinically malignant GISTs. Adjuvant therapy for GISTs, however, still has several problems to be overcome, including the optimal duration of the therapy (more than 2 years may be required), effects on OS, and possible induction of resistance to imatinib [97]. These problems will, we hope, be solved by ongoing trials.

Other multidisciplinary treatments for advanced GIST include neoadjuvant treatment and surgery for imatinib-responding GIST, so-called adjuvant surgery. At present, these treatments should be performed only within clinical trials by a team very familiar with GIST therapy.

\section{Personalized medicine}

Recurrence risk after complete removal of tumors is dependent on the location of the tumors, tumor size, the biological aggressiveness of the tumors, and genotype. Response to imatinib or sunitinib also depends on the location, genotype, biological aggressiveness, and tumor burden. Using best-fitted risk classification with these factors, we could select the patients who required aggressive therapy [98]. We may be able to choose the optimal dose of imatinib and the best-fitted drug depending on genotype. For example, GISTs with KIT exon 9 mutations may be treated with a higher dose of imatinib if tolerable, and GISTs without mutations in the KIT and PDGFRA genes may be treated with sunitinib. This personalized medicine should be based on scientific evidence.

\section{What can we learn from molecular-targeted therapy in GIST?}

Imatinib therapy is the first successful moleculartargeted therapy for solid tumors. What can we learn from this?

First, we could be successful in the development of targeted agents if we use the best-fitted molecules for correct targets of cancer. In this regard, qualitative and quantitative differences between cancer targets and normal tissues seem to be important for achieving high efficacy and low rates of adverse effects. One of the qualitative differences may be mutations, as seen in the KIT and PDGFRA genes, and one of the quantitative differences may be the overexpression of VEGF and PDGF in renal cell carcinoma.

Second, we would have better results when we treat cancer by its molecular nature but not by its location. For example, cetuximab, a chimeric monoclonal antibody to EGFR, had beneficial effects on EGFRoverexpressing colon cancer without ras mutations, but did not have beneficial effects on colon cancer without EGFR overexpression or with ras mutations [99].
Third, even for molecular-targeted agents that have shown high efficacy and safety, cancer inevitably acquires resistance to the drugs during treatment. Right now, overcoming drug resistance is critical for patients receiving chemotherapy. As shown in this review, molecular-targeted agents may become a research model of cancer resistance; because the target is simple, the molecular nature of targeted diseases, including downstream pathways, is sometimes elucidated. Cancers targeted by these agents tend to have a nature addicted to their original driving force, as seen with GIST, CML, and EGFR-mutated non-small cell lung cancer.

In summary, here we have provided an overview of GIST as a molecularly characterized cancer. GIST has gain-of-function mutations in the KIT or PDGFRA gene, which are targets of imatinib as well as sunitinib. Cure can be obtained only by complete removal of a GIST; however, after recurrence or for advanced and/or metastatic GIST, imatinib is indicated. Imatinib showed high efficacy, depending on genotype, and sufficient safety. The drug, however, has met with acquired resistance during treatment, of which the molecular mechanisms have been elucidated to be mostly secondary mutations in the kinase domains of the corresponding targeted genes. Although sunitinib has had substantial effects on imatinib-resistant GIST, this drug has also encountered primary and secondary resistance, depending on the genotype of the imatinib-resistant GIST. Molecular-targeted agents should be developed based on molecular mechanisms.

Acknowledgments This work was partly supported by grants from the Japanese Ministry of Education, Culture, Sports, Science and Technology.

\section{References}

1. Nishida T, Hirota S. Biological and clinical review of stromal tumors in the gastrointestinal tract. Histol Histopathol 2000;15: 1293-301.

2. Rubin BP, Heinrich MC, Corless CL. Gastrointestinal stromal tumor. Lancet 2007;369:1731-41.

3. Hitrota S, Isozaki K, Moriyama Y, Kanakura Y, Nishida T, Ishiguro S, et al. Gain-of-Function mutations of c-kit in human gastrointestinal stromal tumors. Science 1998;279:577-80.

4. Nishida T, Hirota S, Taniguchi M, Hashimoto K, Isozaki K, Nakamura $\mathrm{H}$, et al. Familial gastrointestinal stromal tumors with germ line mutation of the KIT gene. Nat Genet 1998;19:3234.

5. Heinrich MC, Corless CL, Duencing A, McGreevey L, Chen CJ, Joseph N, et al. PDGFRA activating mutations in gastrointestinal stromal tumors. Science 2003;299:708-10.

6. Hirota S, Ohashi A, Nishida T, Isozaki K, Kinoshita K, Shinomura Y, et al. Gain-of-function mutations of platelet-derived growth factor receptor alpha gene in gastrointestinal stromal tumors. Gastroenterology 2003;125:660-7.

7. Demetri GD, Benjamin RS, Blanke CD, Blay JY, Casali P, Choi $\mathrm{H}$, et al. NCCN Task Force report: management of patients with 
gastrointestinal stromal tumor (GIST) - update of the NCCN clinical practice guidelines. J Natl Compr Canc Netw 2007; 5(Suppl 2):s1-s29.

8. Casali PG, Jost L, Reichardt P, Schlemmer M, Blay JY, ESMO Guidelines Working Group. Gastrointestinal stromal tumors: ESMO clinical recommendations for diagnosis, treatment and follow-up. Ann Oncol 2008;19(Suppl 2):ii35-8.

9. Nishida T, Hirota S, Yanagisawa A, Sugino Y, Minami M, Yamamura Y, et al. Clinical practice guideline for gastrointestinal stromal tumor (GIST) in Japan. Int J Clin Oncol 2008;13: 416-30.

10. Demetri GD, von Mehren M, Blanke CD, Van den Abbeele AD, Eisenberg B, Roberts PJ, et al. Efficacy and safety of imatinib mesylate in advanced gastrointestinal stromal tumors. N Engl J Med 2002;347:472-80.

11. Verweij J, Casali PG, Zalcberg J, LeCesne A, Reichardt P, Blay JY, et al. Progression-free survival in gastrointestinal stromal tumours with high-dose imatinib: randomised trial. Lancet 2004;364:1127-34.

12. Blanke CD, Demetri GD, von Mehren M, Heinrich MC, Eisenberg B, Fletcher JA, et al. Long-term results from a randomized phase II trial of standard- versus higher-dose imatinib mesylate for patients with unresectable or metastatic gastrointestinal stromal tumors expressing KIT. J Clin Oncol 2008;26:620-5.

13. Nishida T, Shirao K, Sawaki A, Koseki M, Okamura T, Ohtsu A, et al. Efficacy and safety profile of imatinib mesylate (STI571) in Japanese patients with advanced gastrointestinal stromal tumors: a phase II study (STI571B1202). Int J Clin Oncol 2008;13: 244-51.

14. Blanke CD, Rankin C, Demetri GD, Ryan CW, von Mehren M, Benjamin RS, et al. Phase III randomized, intergroup trial assessing imatinib mesylate at two dose levels in patients with unresectable or metastatic gastrointestinal stromal tumors expressing the kit receptor tyrosine kinase: S0033. J Clin Oncol 2008;26:62632.

15. Blay JY. Pharmacological management of gastrointestinal stromal tumours: an update on the role of sunitinib. Ann Oncol 2009. doi:10.1093/annonc/mdp291.

16. Demetri GD, van Oosterom AT, Garrett CR, Blackstein ME, Shah MH, Verweij J, et al. Efficacy and safety of sunitinib in patients with advanced gastrointestinal stromal tumour after failure of imatinib: a randomised controlled trial. Lancet 2006; 368:1329-38.

17. Chow LQ, Eckhardt SG. Sunitinib: from rational design to clinical efficacy. J Clin Oncol 2007;25:884-96.

18. Lasota J, Miettinen M. Clinical significance of oncogenic KIT and PDGFRA mutations in gastrointestinal stromal tumours. Histopathology 2008;53:245-66.

19. Corless CL, Heinrich MC. Molecular pathobiology of gastrointestinal stromal sarcomas. Annu Rev Pathol 2008;3:557-86.

20. Heinrich MC, Corless CL, Demetri GD, Blanke CD, von Mehren $\mathrm{M}$, Joensuu $\mathrm{H}$, et al. Kinase mutations and imatinib response in patients with metastatic gastrointestinal stromal tumor. J Clin Oncol 2003;21:4342-9.

21. Debiec-Rychter M, Sciot R, Le Cesne A, Schlemmer M, Hohenberger P, van Oosterom AT, et al. KIT mutations and dose selection for imatinib in patients with advanced gastrointestinal stromal tumours. Eur J Cancer 2006;42:1093-103.

22. Heinrich MC, Owzar K, Corless CL, Hollis D, Borden EC, Fletcher CD, et al. Correlation of kinase genotype and clinical outcome in the North American Intergroup Phase III Trial of imatinib mesylate for treatment of advanced gastrointestinal stromal tumor: CALGB 150105 Study by Cancer and Leukemia Group B and Southwest Oncology Group. J Clin Oncol 2008; 26:5360-7.

23. Corless CL, Schroeder A, Griffith D, Town A, McGreevey L, Harrell P, et al. PDGFRA mutations in gastrointestinal stromal tumors: frequency, spectrum and in vitro sensitivity to imatinib. Clin Oncol 2005;23:5357-64.
24. Nishida T, Takahashi T, Nakajima K, Tsujinaka T, Hirota S. KIT and PDGFRA mutations of gastrointestinal stromal tumor. J Clin Oncol 2009;27:15s (Suppl; abstract 10560).

25. Roskoski R Jr. Structure and regulation of Kit protein-tyrosine kinase - the stem cell factor receptor. Biochem Biophys Res Commun 2005;338:1307-15.

26. Lasota J, Dansonka-Mieszkowska A, Stachura T, SchneiderStock R, Kallajoki M, Steigen SE, et al. Gastrointestinal stromal tumors with internal tandem duplications in $3^{\prime}$ end of KIT juxtamembrane domain occur predominantly in stomach and generally seem to have a favorable course. Mod Pathol 2003;16:125764.

27. Gajiwala KS, Wu JC, Christensen J, Deshmukh GD, Diehl W, DiNitto JP, et al. KIT kinase mutants show unique mechanisms of drug resistance to imatinib and sunitinib in gastrointestinal stromal tumor patients. Proc Natl Acad Sci U S A 2009;106: $1542-7$.

28. Wardelmann E, Losen I, Hans V, Neidt I, Speidel N, Bierhoff E, et al. Deletion of Trp-557 and Lys-558 in the juxtamembrane domain of the c-kit protooncogene is associated with metastatic behavior of gastrointestinal stromal tumors. Int $\mathrm{J}$ Cancer 2003;106:887-95.

29. Kikuchi H, Yamamoto M, Hiramatsu Y, Baba M, Ohta M, Kamiya K, et al. Effect of loss of heterozygosity of the c-kit gene on prognosis after hepatectomy for metastatic liver gastrointestinal stromal tumors. Cancer Sci 2007;98:1734-9.

30. Lasota J, vel Dobosz AJ, Wasag B, Wozniak A, Kraszewska E, Michej W, et al. Presence of homozygous KIT exon 11 mutations is strongly associated with malignant clinical behavior in gastrointestinal stromal tumors. Lab Invest 2007;87:1029-41.

31. Hartmann K, Wardelmann E, Ma Y, Merkelbach-Bruse S, Preussner LM, Woolery C, et al. Novel germline mutation of KIT associated with familial gastrointestinal stromal tumors and mastocytosis. Gastroenterology 2005;129:1042-6.

32. Hirota S, Okazaki T, Kitamura Y, O'Brien P, Kapusta L, Dardick I. Cause of familial and multiple gastrointestinal autonomic nerve tumors with hyperplasia of interstitial cells of Cajal is germline mutation of the c-kit gene. Am J Surg Pathol 2000;24: 326-7.

33. Beghini A, Tibiletti MG, Roversi G, Chiaravalli AM, Serio G, Capella C, Larizza L. Germline mutation in the juxtamembrane domain of the kit gene in a family with gastrointestinal stromal tumors and urticaria pigmentosa. Cancer 2001;92:657-62.

34. Maeyama H, Hidaka E, Ota H, Minami S, Kajiyama M, Kuraishi A, et al. Familial gastrointestinal stromal tumor with hyperpigmentation: association with a germline mutation of the c-kit gene. Gastroenterology 2001;120:210-15.

35. Robson ME, Glogowski E, Sommer G, Antonescu CR, Nafa K, Maki RG, et al. Pleomorphic characteristics of a germ-line KIT mutation in a large kindred with gastrointestinal stromal tumors, hyperpigmentation, and dysphagia. Clin Cancer Res 2004;10: 1250-4.

36. Carballo M, Roig I, Aguilar F, Pol MA, Gamundi MJ, Hernan I, Martinez-Gimeno M. Novel c-KIT germline mutation in a family with gastrointestinal stromal tumors and cutaneous hyperpigmentation. Am J Med Genet A 2005;132:361-4.

37. Li FP, Fletcher JA, Heinrich MC, Garber JE, Sallan SE, CurielLewandrowski $\mathrm{C}$, et al. Familial gastrointestinal stromal tumor syndrome: phenotypic and molecular features in a kindred. J Clin Oncol 2005;23:2735-43.

38. Kim HJ, Lim SJ, Park K, Yuh YJ, Jang SJ, Choi J. Multiple gastrointestinal stromal tumors with a germline c-kit mutation. Pathol Int 2005;55:655-9.

39. Kang DY, Park CK, Choi JS, Jin SY, Kim HJ, Joo M, et al. Multiple gastrointestinal stromal tumors: clinicopathologic and genetic analysis of 12 patients. Am J Surg Pathol 2007;31: 224-32.

40. Lasota J, Miettinen M. A new familial GIST identified. Am J Surg Pathol 2006;30:1342. 
41. Tarn C, Merkel E, Canutescu AA, Shen W, Skorobogatko Y, Heslin MJ, et al. Analysis of KIT mutations in sporadic and familial gastrointestinal stromal tumors: therapeutic implications through protein modeling. Clin Cancer Res 2005;11:366877.

42. Kleinbaum EP, Lazar AJ, Tamborini E, Mcauliffe JC, Sylvestre PB, Sunnenberg TD, et al. Clinical, histopathologic, molecular and therapeutic findings in a large kindred with gastrointestinal stromal tumor. Int J Cancer 2008;122:711-18.

43. Woźniak A, Rutkowski P, Sciot R, Ruka W, Michej W, DebiecRychter M. Rectal gastrointestinal stromal tumors associated with a novel germline KIT mutation. Int J Cancer 2008;122: 2160-4.

44. Isozaki K, Terris B, Belghiti J, Schiffmann S, Hirota S, Vanderwinden JM. Germline-activating mutation in the kinase domain of KIT gene in familial gastrointestinal stromal tumors. Am J Pathol 2000;157:1581-5.

45. Graham J, Debiec-Rychter M, Corless CL, Reid R, Davidson $\mathrm{R}$, White JD. Imatinib in the management of multiple gastrointestinal stromal tumors associated with a germline KIT K642E mutation. Arch Pathol Lab Med 2007;131:13936.

46. Hirota S, Nishida T, Isozaki K, Taniguchi M, Nishikawa K, Ohashi A, et al. Familial gastrointestinal stromal tumors associated with dysphagia and novel type germline mutation of KIT gene. Gastroenterology 2002;122:1493-9.

47. O'Riain C, Corless CL, Heinrich MC, Keegan D, Vioreanu M, Maguire D, et al. Gastrointestinal stromal tumors: insights from a new familial GIST kindred with unusual genetic and pathologic features. Am J Surg Pathol 2005;29:1680-3.

48. Thalheimer A, Schlemmer M, Bueter M, Merkelbach-Bruse S, Schildhaus HU, Buettner R, et al. Familial gastrointestinal stromal tumors caused by the novel KIT exon 17 germline mutation N822Y. Am J Surg Pathol 2008;32:1560-5.

49. de Raedt T, Cools J, Debiec-Rychter M, Brems H, Mentens N, Sciot R, et al. Intestinal neurofibromatosis is a subtype of familial GIST and results from a dominant activating mutation in PDGFRA. Gastroenterology 2006;131:1907-12.

50. Pasini B, Matyakhina L, Bei T, Muchow M, Boikos S, Ferrando $\mathrm{B}$, et al. Multiple gastrointestinal stromal and other tumors caused by platelet-derived growth factor receptor alpha gene mutations: a case associated with a germline V561D defect. J Clin Endocrinol Metab 2007;92:3728-32.

51. Chompret A, Kannengiesser C, Barrois M, Terrier P, Dahan P, Tursz T, et al. PDGFRA germline mutation in a family with multiple cases of gastrointestinal stromal tumor. Gastroenterology 2004;126:318-21.

52. Nishida T, Hirota S, Matsuda H, Kitamura Y. Familial gastrointestinal stromal tumors as a cancer syndrome. Gann Monogr Cancer Res 2004;53:59-66.

53. Sommer G, Agosti V, Ehlers I, Rossi F, Corbacioglu S, Farkas J, et al. Gastrointestinal stromal tumors in a mouse model by targeted mutation of the Kit receptor tyrosine kinase. Proc Natl Acad Sci U S A 2003;100:6706-11.

54. Nakai N, Ishikawa T, Nishitani A, Liu NN, Shincho M, Hao H, et al. A mouse model of a human multiple GIST family with KITAsp820Tyr mutation generated by a knock-in strategy. J Pathol 2008;214:302-11.

55. Longley BJ Jr, Metcalfe DD, Tharp M, Wang X, Tyrrell L, Lu SZ, et al. Activating and dominant inactivating c-KIT catalytic domain mutations in distinct clinical forms of human mastocytosis. Proc Natl Acad Sci U S A 1999;96:1609-14.

56. Longley BJ, Tyrrell L, Lu SZ, Ma YS, Langley K, Ding TG, et al. Somatic c-KIT activating mutation in urticaria pigmentosa and aggressive mastocytosis: establishment of clonality in a human mast cell neoplasm. Nat Genet 1996;12:312-24.

57. Curtin JA, Busam K, Pinkel D, Bastian BC. Somatic activation of KIT in distinct subtypes of melanoma. J Clin Oncol 2006; 24:4340-6.
58. Kawanowa K, Sakuma Y, Sakurai S, Hishima T, Iwasaki Y, Saito $\mathrm{K}$, et al. High incidence of microscopic gastrointestinal stromal tumors in the stomach. Hum Pathol 2006;37:1527-35.

59. Agaimy A, Wünsch PH, Dirnhofer S, Bihl MP, Terracciano LM, Tornillo L. Microscopic gastrointestinal stromal tumors in esophageal and intestinal surgical resection specimens: a clinicopathologic, immunohistochemical, and molecular study of 19 lesions. Am J Surg Pathol 2008;32:867-73.

60. Abraham SC, Krasinskas AM, Hofstetter WL, Swisher SG, Wu TT. "Seedling" mesenchymal tumors (gastrointestinal stromal tumors and leiomyomas) are common incidental tumors of the esophagogastric junction. Am J Surg Pathol 2007;31:162935 .

61. Corless CL, McGreevey L, Haley A, Town A, Heinrich MC. KIT mutations are common in incidental gastrointestinal stromal tumors $1 \mathrm{~cm}$ or less in size. Am J Pathol 2002;160:1567-72.

62. Heinrich MC, Maki RG, Corless CL, Antonescu CR, Harlow A, Griffith D, et al. Primary and secondary kinase genotypes correlate with the biological and clinical activity of sunitinib in imatinib-resistant gastrointestinal stromal tumor. J Clin Oncol 2008;26:5352-9.

63. Nishida T, Takahashi T, Nishitani A, Doi T, Shirao K, Komatsu $\mathrm{Y}$, et al. Sunitinib-resistant gastrointestinal stromal tumors harbor cis-mutations in the activation loop of the KIT gene. Int J Clin Oncol 2009;14:143-9.

64. Gajiwala KS, Wu JC, Christensen J, Deshmukh GD, Diehl W, DiNitto JP, et al. KIT kinase mutants show unique mechanisms of drug resistance to imatinib and sunitinib in gastrointestinal stromal tumor patients. Proc Natl Acad Sci U S A 2009;106: 1542-7.

65. van Oosterom AT, Judson I, Verweij J, Stroobants S, Donato di Paola E, Dimitrijevic S, et al. Safety and efficacy of imatinib (STI571) in metastatic gastrointestinal stromal tumours: a phase I study. Lancet 2001;358:1421-3.

66. Le Cesne A, Van Glabbeke M, Verweij J, Casali PG, Findlay M, Reichardt $\mathrm{P}$, et al. Absence of progression as assessed by response evaluation criteria in solid tumors predicts survival in advanced GI stromal tumors treated with imatinib mesylate: the intergroup EORTC-ISG-AGITG phase III trial. J Clin Oncol 2009;27: 3969-74.

67. Blay JY, Le Cesne A, Ray-Coquard I, Bui B, Duffaud F, Delbaldo $\mathrm{C}$, et al. Prospective multicentric randomized phase III study of imatinib in patients with advanced gastrointestinal stromal tumors comparing interruption versus continuation of treatment beyond 1 year: the French Sarcoma Group. J Clin Oncol 2007;25:1107-13.

68. Demetri GD, Wang Y, Wehrle E, Racine A, Nikolova Z, Blanke $\mathrm{CD}$, et al. Imatinib plasma levels are correlated with clinical benefit in patients with unresectable/metastatic gastrointestinal stromal tumors. J Clin Oncol 2009;27:3141-7.

69. Van Glabbeke M, Verweij J, Casali PG, Le Cesne A, Hohenberger P, Ray-Coquard I, et al. Initial and late resistance to imatinib in advanced gastrointestinal stromal tumors are predicted by different prognostic factors: a European Organisation for Research and Treatment of Cancer-Italian Sarcoma GroupAustralasian Gastrointestinal Trials Group study. J Clin Oncol 2005;23:5795-804.

70. George S, Blay JY, Casali PG, Le Cesne A, Stephenson P, Deprimo SE, et al. Clinical evaluation of continuous daily dosing of sunitinib malate in patients with advanced gastrointestinal stromal tumour after imatinib failure. Eur J Cancer 2009;45: 1959-68.

71. Shirao K, Nishida T, Doi T, Komatsu Y, Muro K, Li Y, et al. Phase I/II study of sunitinib malate in Japanese patients with gastrointestinal stromal tumor after failure of prior treatment with imatinib mesylate. Invest New Drugs 2009. doi:10.1007/ s10637-009-9306-9.

72. Shankar S, vanSonnenberg E, DiPiro P, Dipiro PJ, Van Den Abbeele A, Demetri GD, et al. Gastrointestinal stromal tumor: 
new nodule-within-a-mass pattern of recurrence after partial response to imatinib mesylate. Radiology 2005;235:892-8.

73. Liegl B, Hornick JL, Antonescu CR, Corless CL, Fletcher CD. Rhabdomyosarcomatous differentiation in gastrointestinal stromal tumors after tyrosine kinase inhibitor therapy: a novel form of tumor progression. Am J Surg Pathol 2009;33:218-26.

74. Heinrich MC, Corless CL, Blanke CD, Demetri GD, Joensuu H, Roberts PJ, et al. Molecular correlates of imatinib resistance in gastrointestinal stromal tumors. J Clin Oncol 2006;24:4764-74.

75. Antonescu CA, Besmar P, Tianhua G, Arkun K, Hom G, Koryotowski B, et al. Acquired resistance to imatinib in gastrointestinal stromal tumor occurs through secondary gene mutation. Clin Cancer Res 2005;11:4182-90.

76. Wakai T, Kanda T, Hirota S, Ohashi A, Shirai Y, Hatakeyama $K$. Late resistance to imatinib therapy in a metastatic gastrointestinal stromal tumour is associated with a second KIT mutation. Br J Cancer 2004;90:2059-61.

77. Tamborini E, Bonadiman L, Greco A, Albertini V, Negri T, Gronchi A, et al. A new mutation in the KIT ATP pocket causes acquired resistance to imatinib in a gastrointestinal stromal tumor patient. Gastroenterology 2004;127:294-9.

78. Chen LL, Trent JC, Wu EF, Fuller GN, Ramdas L, Zhang W, et al. A missense mutation in KIT kinase domain 1 correlates with imatinib resistance in gastrointestinal stromal tumors. Cancer Res 2004;64:5913-19.

79. Debiec-Rychter M, Cools J, Dumez H, Sciot R, Stul M, Mentens $\mathrm{N}$, et al. Mechanism of resistance to imatinib mesylate in gastrointestinal stromal tumors and activity of the PKC412 inhibitor against imatinib-resistant mutants. Gastroenterology 2005;128: 270-9

80. Wardelmann E, Merkelbach-Bruse S, Pauls K, Thomas N, Schildhaus HU, Heinicke T, et al. Polyclonal evolution of multiple secondary KIT mutations in gastrointestinal stromal tumors under treatment with imatinib mesylate. Clin Cancer Res 2006; 12:1743-9.

81. Nishida T, Kanda T, Nishitani A, Takahashi T, Nakajima K, Ishikawa $\mathrm{T}$, et al. Secondary mutations in the kinase domain of the KIT gene are predominant in imatinib-resistant gastrointestinal stromal tumor. Cancer Sci 2008;99:799-804.

82. Agaram NP, Besmer P, Wong GC, Guo T, Socci ND, Maki RG, et al. Pathologic and molecular heterogeneity in imatinib-stable or imatinib-responsive gastrointestinal stromal tumors. Clin Cancer Res 2007;13:170-81.

83. Miselli FC, Casieri P, Negri T, Orsenigo M, Lagonigro MS, Gronchi A, et al. c-Kit/PDGFRA gene status alterations possibly related to primary imatinib resistance in gastrointestinal stromal tumors. Clin Cancer Res 2007;13:2369-7237.

84. Liegl B, Kepten I, Le C, Zhu M, Demetri GD, Heinrich MC, et al. Heterogeneity of kinase inhibitor resistance mechanisms in GIST. J Pathol 2008;216:64-74.

85. Grimpen F, Yip D, McArthur G, Waring P, Goldstein D, Loughrey M, et al. Resistance to imatinib, low-grade FDG-avidity on PET, and acquired KIT exon 17 mutation in gastrointestinal stromal tumour. Lancet Oncol 2005;6:724-7.

86. Lim KH, Huang MJ, Chen LT, Wang TE, Liu CL, Chang CS, et al. Molecular analysis of secondary kinase mutations in imatinib- resistant gastrointestinal stromal tumors. Med Oncol 2008;25: 207-13.

87. Michor F, Hughes TP, Iwasa Y, Branford S, Shah NP, Sawyers CL, et al. Dynamics of chronic myeloid leukaemia. Nature 2005;435:1267-70.

88. Jiang X, Saw KM, Eaves A, Eaves C. Instability of BCR-ABL gene in primary and cultured chronic myeloid leukemia stem cells. J Natl Cancer Inst 2007;99:680-93.

89. Guo T, Agaram NP, Wong GC, Hom G, D'Adamo D, Maki RG, et al. Sorafenib inhibits the imatinib-resistant KITT670I gatekeeper mutation in gastrointestinal stromal tumor. Clin Cancer Res 2007;13:4874-81.

90. Roberts KG, Odell AF, Byrnes EM, Baleato RM, Griffith R, Lyons AB, et al. Resistance to c-KIT kinase inhibitors conferred by V654A mutation. Mol Cancer Ther 2007;6:1159-66.

91. Shah NP, Nicoll JM, Nagar B, Gorre ME, Paquette RL, Kuriyan $\mathrm{J}$, et al. Multiple BCR-ABL kinase domain mutations confer polyclonal resistance to the tyrosine kinase inhibitor imatinib (STI571) in chronic phase and blast crisis chronic myeloid leukemia. Cancer Cell 2002;2:117-25.

92. Cools J, DeAngelo DJ, Gotlib J, Stover EH, Legare RD, Cortes $\mathrm{J}$, et al. A tyrosine kinase created by fusion of the PDGFRA and FIP1L1 genes as a therapeutic target of imatinib in idiopathic hypereosinophilic syndrome. N Engl J Med 2003;348:1201-14.

93. Kobayashi S, Boggon TJ, Dayaram T, Jänne PA, Kocher O, Meyerson M, et al. EGFR mutation and resistance of non-smallcell lung cancer to gefitinib. N Engl J Med 2005;352:786-92.

94. Tamborini E, Pricl S, Negri T, Lagonigro MS, Miselli F, Greco A, et al. Functional analyses and molecular modeling of two c-Kit mutations responsible for imatinib secondary resistance in GIST patients. Oncogene 2006;25:6140-6.

95. Bell DW, Gore I, Okimoto RA, Godin-Heymann N, Sordella R, Mulloy R, et al. Inherited susceptibility to lung cancer may be associated with the T790M drug resistance mutation in EGFR. Nat Genet 2005;37:1315-16.

96. Dematteo RP, Ballman KV, Antonescu CR, Maki RG, Pisters PW, Demetri GD, et al. Adjuvant imatinib mesylate after resection of localised, primary gastrointestinal stromal tumour: a randomised, double-blind, placebo-controlled trial. Lancet 2009;373: 1097-104.

97. Gronchi A, Judson I, Nishida T, Poveda A, Martin J, Reichardt P, et al. Adjuvant treatment of GIST with imatinib: solid ground or still quicksand? A comment on behalf of the EORTC Soft Tissue and Bone Sarcoma Group, the Italian Sarcoma Group, the NCRI Sarcoma Clinical Studies Group (UK), the Japanese Study Group on GIST, the French Sarcoma Group and the Spanish Sarcoma Group (GEIS). Eur J Cancer 2009;45:1103-6.

98. Gold JS, Gönen M, Gutiérrez A, Broto JM, García-Del-Muro X, Smyrk TC, et al. Development and validation of a prognostic nomogram for recurrence-free survival after complete surgical resection of localised primary gastrointestinal stromal tumour: a retrospective analysis. Lancet Oncol 2009;10:1045-52.

99. Karapetis CS, Khambata-Ford S, Jonker DJ, O'Callaghan CJ, Tu D, Tebbutt NC, et al. K-ras mutations and benefit from cetuximab in advanced colorectal cancer. N Engl J Med 2008;359: $1757-65$. 